\title{
Univalence conditions for a general integral operator
}

\section{Adriana Oprea and Daniel Breaz}

\begin{abstract}
For analytic functions in the open unit disk $U$, we define a new general integral operator. The main object of the this paper is to study this new integral operator and to determine univalence conditions of it. Several corollaries of the main results are also considered.
\end{abstract}

\section{Introduction}

Let $\mathcal{A}$ denote the class of function of the form:

$$
f(z)=z+\sum_{i=2}^{\infty} a_{n} z^{n}
$$

which are analytic in the open unit disc $\mathcal{U}=\{z:|z|<1\}$

Further, by $S$ we shall denote the class of functions in $\mathcal{A}$ which are univalent in $\mathcal{U}$.

In [9], Silverman define the class $G_{b}$.

For $0<b \leq 1$, he considered the class:

$$
G_{b}=\left\{f \in \mathcal{A}:\left|1+\frac{z f^{\prime \prime}(z)}{f^{\prime}(z)}-\frac{z f^{\prime}(z)}{f(z)}\right|<b\left|\frac{z f^{\prime}(z)}{f(z)}\right|, z \in \mathcal{U}\right\}
$$

Key Words: Analytic functions; Integral Operators; General Schwarz Lemma 2010 Mathematics Subject Classification: Primary 30C45; Secondary 30C75 Received: 2 May, 2014.

Revised: 30 May, 2014.

Accepted: 27 June, 2014. 
Let $\alpha_{i} \in \mathbb{C}^{*}$, for all $i=1,2, \ldots n, n \in \mathbb{N}^{*}, \gamma \in \mathbb{C}$, with $\operatorname{Re} \gamma>0$.

We consider $I_{\gamma, \alpha_{i}}: \mathcal{A}^{n} \times \mathcal{A}^{n} \rightarrow \mathcal{A}$ be the integral operator defined by:

$$
\begin{gathered}
I_{\gamma, \alpha_{i}}\left(f_{1}, \ldots f_{n}, g_{1}, \ldots g_{n}\right)(z)= \\
\left\{\gamma \int_{0}^{z} t^{\gamma-1}\left(\frac{f_{1}(t)}{t}\right)^{1-\frac{1}{\alpha_{1}}}\left(g_{1}^{\prime}(t)\right)^{\frac{1}{\alpha_{1}}} \ldots\left(\frac{f_{n}(t)}{t}\right)^{1-\frac{1}{\alpha_{n}}}\left(g_{n}^{\prime}(t)\right)^{\frac{1}{\alpha_{n}}} d t\right\}^{\frac{1}{\gamma}}
\end{gathered}
$$

In the present paper we study the univalence conditions for the integral operator $I_{\gamma, \alpha_{i}}\left(f_{1}, \ldots f_{n}, g_{1}, \ldots g_{n}\right)$, when $g_{i} \in G_{b_{i}}$ and $f_{i} \in \mathcal{A}$ for all $i=1, \ldots, n$. Also, the univalence of some integral operators has been studied by other authors like V. Pescar and D. Breaz in work [8].

In order to derive our main results, we have to recall here the following univalence criteria.

Theorem 1. [5] Let $f \in \mathcal{A}$ and $\gamma \in \mathbb{C}$. If $\operatorname{Re} \gamma>0$ and

$$
\frac{1-|z|^{2 \operatorname{Re} \gamma}}{\operatorname{Re} \gamma}\left|\frac{z f^{\prime \prime}(z)}{f^{\prime}(z)}\right| \leq 1
$$

for all $z \in \mathcal{U}$, then the integral operator

$$
F_{\gamma}(z)=\left(\gamma \int_{0}^{z} t^{\gamma-1} f^{\prime}(t) d t\right)^{\frac{1}{\gamma}}
$$

is in the class $\mathcal{S}$.

Theorem 2. [6] Let $\delta \in \mathbb{C}$ with $\operatorname{Re} \delta>0$. If $f \in \mathcal{A}$ satisfies

$$
\frac{1-|z|^{2 \operatorname{Re} \delta}}{\operatorname{Re} \delta}\left|\frac{z f^{\prime \prime}(z)}{f^{\prime}(z)}\right| \leq 1
$$

for all $z \in \mathcal{U}$, then, for any complex $\gamma$ with $\operatorname{Re} \gamma \geq \operatorname{Re} \delta$, the integral operator

$$
F_{\gamma}(z)=\left(\gamma \int_{0}^{z} t^{\gamma-1} f^{\prime}(t) d t\right)^{\frac{1}{\gamma}}
$$

is in the class $S$.

Theorem 3. [7] Let $\gamma$ be a complex number, $\operatorname{Re} \gamma>0$, and $c$ a complex number, $|c| \leq 1, c \neq-1$. If $f \in \mathcal{A}$ satisfies

$$
\left.|c| z\right|^{2 \gamma}+\left(1-|z|^{2 \gamma}\right) \frac{z f^{\prime \prime}(z)}{\gamma f^{\prime}(z)} \mid \leq 1
$$


for all $z \in \mathcal{U}$, then the integral operator

$$
F_{\gamma}(z)=\left(\gamma \int_{0}^{z} t^{\gamma-1} f^{\prime}(t) d t\right)^{\frac{1}{\gamma}}
$$

is in the class $S$.

Also, we need the following general Schwarz Lemma

Lemma 1. (General Schwarz-Lemma) [4] Let the function $f$ be regular in the disk $\mathcal{U}_{R}=\{z \in \mathbb{C}:|z|<R\}$, with $|f(z)|<M$, $M$ fixed. If $f$ has one zero with multiplicity greater then $m$ for $z=0$, then

$$
|f(z)| \leq \frac{M}{R^{m}}|z|^{m}, \quad z \in \mathcal{U}_{R}
$$

the equality can hold only if

$$
f(z)=e^{i \theta} \frac{M}{R^{m}} z^{m}
$$

where $\theta$ is constant.

2 Univalence conditions for $I_{\gamma, \alpha_{i}}\left(f_{1}, \ldots f_{n}, g_{1}, \ldots g_{n}\right)(z)$

First, we prove:

Theorem 4. Let $\gamma \in \mathbb{C}$ and $\alpha_{i} \in \mathbb{C}^{*}$ for all $i=1, \ldots n$, with

$$
\operatorname{Re} \gamma \geq \sum_{\mathrm{i}=1}^{\mathrm{n}} \frac{1}{\left|\alpha_{\mathrm{i}}\right|}\left(\left|\alpha_{\mathrm{i}}-1\right|+2 \mathrm{~b}_{\mathrm{i}}+1\right)
$$

If for all $i=1, \ldots, n, g_{i} \in G_{b_{i}} ; 0<b_{i} \leq 1, f_{i} \in \mathcal{A}$, and

$$
\left|\frac{z f_{i}^{\prime}(z)}{f_{i}(z)}-1\right|<1, z \in \mathcal{U}\left|\frac{z g_{i}^{\prime}(z)}{g_{i}(z)}-1\right|<1, z \in \mathcal{U}
$$

then the integral operator $I_{\gamma, \alpha_{i}}\left(f_{1}, \ldots f_{n}, g_{1}, \ldots g_{n}\right)$, defined by (3) is in the class $S$.

Proof. We define:

$$
h(z)=\int_{0}^{z} \prod_{i=1}^{n}\left[\left(\frac{f_{i}(t)}{t}\right)^{1-\frac{1}{\alpha_{i}}}\left(g_{i}^{\prime}(t)\right)^{\frac{1}{\alpha_{i}}}\right] d t
$$


so, that, obviously, we get:

$$
h^{\prime}(z)=\prod_{i=1}^{n}\left[\left(\frac{f_{i}(z)}{z}\right)^{1-\frac{1}{\alpha_{i}}}\left(g_{i}^{\prime}(z)\right)^{\frac{1}{\alpha_{i}}}\right]
$$

and

$$
\begin{gathered}
\frac{z h^{\prime \prime}(z)}{h^{\prime}(z)}=\sum_{i=1}^{n}\left[\left(1-\frac{1}{\alpha_{i}}\right)\left(\frac{z f_{i}^{\prime}(z)}{f_{i}(z)}-1\right)+\frac{1}{\alpha_{i}} \frac{z g_{i}^{\prime \prime}(z)}{g_{i}^{\prime}(z)}\right] \\
=\sum_{i=1}^{n}\left[\left(1-\frac{1}{\alpha_{i}}\right)\left(\frac{z f_{i}^{\prime}(z)}{f_{i}(z)}-1\right)+\frac{1}{\alpha_{i}}\left(\frac{z g_{i}^{\prime \prime}(z)}{g_{i}^{\prime}(z)}-\frac{z g_{i}^{\prime}(z)}{g_{i}(z)}+1\right)+\frac{1}{\alpha_{i}}\left(\frac{z g_{i}^{\prime}(z)}{g_{i}(z)}-1\right)\right]
\end{gathered}
$$

Since $g_{i} \in G_{b_{i}} ; 0<b_{i} \leq 1$ for all $i=1, \ldots n$, from (2) and (6) we obtain:

$$
\begin{gathered}
\leq \sum_{i=1}^{n}\left[\frac{\left|\alpha_{i}-1\right|}{\left|\alpha_{i}\right|}\left|\frac{z f_{i}^{\prime}(z)}{f_{i}(z)}-1\right|+\frac{1}{\left|\alpha_{i}\right|}\left|\frac{z h_{i}^{\prime \prime}(z)}{h_{i}^{\prime}(z)}-\frac{z g_{i}^{\prime}(z)}{g_{i}(z)}+1\right|+\frac{1}{\left|\alpha_{i}\right|}\left|\frac{z g_{i}^{\prime}(z)}{g_{i}(z)}-1\right|\right] \\
\leq \sum_{i=1}^{n}\left[\frac{\left|\alpha_{i}-1\right|}{\left|\alpha_{i}\right|}\left|\frac{z f_{i}^{\prime}(z)}{f_{i}(z)}-1\right|+\frac{1}{\left|\alpha_{i}\right|} b_{i}\left|\frac{z g_{i}^{\prime}(z)}{g_{i}(z)}\right|+\frac{1}{\left|\alpha_{i}\right|}\left|\frac{z g_{i}^{\prime}(z)}{g_{i}(z)}-1\right|\right] \\
\leq \sum_{i=1}^{n}\left[\frac{\left|\alpha_{i}-1\right|}{\left|\alpha_{i}\right|}\left|\frac{z f_{i}^{\prime}(z)}{f_{i}(z)}-1\right|+\frac{1}{\left|\alpha_{i}\right|} b_{i}\left(\left|\frac{z g_{i}^{\prime}(z)}{g_{i}(z)}-1\right|+1\right)+\frac{1}{\left|\alpha_{i}\right|}\left|\frac{z g_{i}^{\prime}(z)}{g_{i}(z)}-1\right|\right] \\
=\sum_{i=1}^{n}\left[\frac{\left|\alpha_{i}-1\right|}{\left|\alpha_{i}\right|}\left|\frac{z f_{i}^{\prime}(z)}{f_{i}(z)}-1\right|+\frac{1}{\left|\alpha_{i}\right|} b_{i}\left|\frac{z g_{i}^{\prime}(z)}{g_{i}(z)}-1\right|+\frac{1}{\left|\alpha_{i}\right|} b_{i}+\frac{1}{\left|\alpha_{i}\right|}\left|\frac{z g_{i}^{\prime}(z)}{g_{i}(z)}-1\right|\right] \\
=\sum_{i=1}^{n}\left[\frac{\left|\alpha_{i}-1\right|}{\left|\alpha_{i}\right|}\left|\frac{z f_{i}^{\prime}(z)}{f_{i}(z)}-1\right|+\frac{1}{\left|\alpha_{i}\right|}\left(b_{i}+1\right)\left|\frac{z g_{i}^{\prime}(z)}{g_{i}(z)}-1\right|+\frac{1}{\left|\alpha_{i}\right|} b_{i}\right] \\
\leq \sum_{i=1}^{n}\left[\frac{\left|\alpha_{i}-1\right|}{\left|\alpha_{i}\right|}+\frac{1}{\left|\alpha_{i}\right|}\left(b_{i}+1\right)+\frac{1}{\left|\alpha_{i}\right|} b_{i}\right] \\
\leq \sum_{i=1}^{n} \frac{1}{\left|\alpha_{i}\right|}\left(\left|\alpha_{i}-1\right|+2 b_{i}+1\right),
\end{gathered}
$$

which shows that:

$$
\begin{gathered}
\frac{1-|z|^{2 \operatorname{Re} \gamma}}{\operatorname{Re} \gamma}\left|\frac{z h^{\prime \prime}(z)}{h^{\prime}(z)}\right| \leq \frac{1-|z|^{2 \operatorname{Re} \gamma}}{\operatorname{Re} \gamma}\left(\sum_{i=1}^{n} \frac{1}{\left|\alpha_{i}\right|}\left(\left|\alpha_{i}-1\right|+2 b_{i}+1\right)\right) \\
\leq \frac{1}{\operatorname{Re} \gamma}\left(\sum_{i=1}^{n} \frac{1}{\left|\alpha_{i}\right|}\left(\left|\alpha_{i}-1\right|+2 b_{i}+1\right)\right) \leq 1
\end{gathered}
$$

Applying Theorem 1 for the function $h$, we prove that the integral operator $I_{\gamma, \alpha_{i}}\left(f_{1}, \ldots f_{n}, g_{1}, \ldots g_{n}\right)$ is in the class $S$. 
Let $\alpha_{i}=1$ for all $i=1,2, \ldots n$ in the Theorem 4 , we have:

Corollary 1. Let $\gamma \in \mathbb{C}$ with

$$
\operatorname{Re} \gamma \geq \sum_{i=1}^{n}\left(2 b_{i}+1\right)
$$

If for all $i=1, \ldots, n, g_{i} \in G_{b_{i}} ; 0<b_{i} \leq 1$ and

$$
\left|\frac{z g_{i}^{\prime}(z)}{g_{i}(z)}-1\right|<1, z \in \mathcal{U}
$$

then the integral operator

$$
I_{\gamma}\left(g_{1}, \ldots, g_{n}\right)(z)=\left\{\gamma \int_{0}^{z} t^{\gamma-1} \prod_{i=1}^{n}\left(g_{i}^{\prime}(t)\right) d t\right\}^{\frac{1}{\gamma}}
$$

is in the class $S$.

Let $n=1, \alpha_{1}=\alpha, b_{1}=b$ and $f_{1}=f, g_{1}=g$ in Theorem 4, we have:

Corollary 2. Let $\gamma \in \mathbb{C}$ and $\alpha \in \mathbb{C}^{*}$ with

$$
\operatorname{Re} \gamma \geq \frac{1}{|\alpha|}(|\alpha-1|+2 \mathrm{~b}+1)
$$

If $f \in \mathcal{A}, g \in G_{b} ; 0<b \leq 1$ and

$$
\left|\frac{z f^{\prime}(z)}{f(z)}-1\right|<1,\left|\frac{z g^{\prime}(z)}{g(z)}-1\right|<1, z \in \mathcal{U},
$$

then the integral operator defined by

$$
I_{\gamma, \alpha}(f, g)(z)=\left\{\gamma \int_{0}^{z} t^{\gamma-1+\frac{1}{\alpha}}\left(\frac{g^{\prime}(t)}{f(t)}\right)^{\frac{1}{\alpha}} \frac{f(t)}{t} d t\right\}^{\frac{1}{\gamma}}
$$

is in the class $S$.

Using Theorem 2 and Schwarz Lemma, we prove:

Theorem 5. Let $\alpha_{i} \in \mathbb{C}^{*}, M_{i} \geq 1, N_{i} \geq 1$, for all $i=1, \ldots, n$ and $\delta \in \mathbb{C}$ with

$$
\operatorname{Re} \delta \geq \sum_{\mathrm{i}=1}^{\mathrm{n}} \frac{1}{\left|\alpha_{\mathrm{i}}\right|}\left[\left|\alpha_{\mathrm{i}}-1\right|\left(2 \mathrm{M}_{\mathrm{i}}+1\right)+\left(\mathrm{b}_{\mathrm{i}}+1\right)\left(2 \mathrm{~N}_{\mathrm{i}}+1\right)+\mathrm{b}_{\mathrm{i}}\right]
$$


If for all $i=1, \ldots, n, f_{i} \in \mathcal{A}, g_{i} \in G_{b_{i}} ; 0<b_{i} \leq 1$ satisfy

$$
\left|\frac{z^{2} f_{i}^{\prime}(z)}{\left[f_{i}(z)\right]^{2}}-1\right|<1,\left|\frac{z^{2} g_{i}^{\prime}(z)}{\left[g_{i}(z)\right]^{2}}-1\right|<1, z \in \mathcal{U}
$$

and

$$
\left|f_{i}(z)\right| \leq M_{i},\left|g_{i}(z)\right| \leq N_{i}, z \in \mathcal{U}, i=1, \ldots n,
$$

then for any complex number $\gamma$ with $\operatorname{Re} \gamma \geq \operatorname{Re} \delta$, the integral operator $I_{\gamma, \alpha_{i}}\left(f_{1}, \ldots f_{n}, g_{1}, \ldots g_{n}\right)$ defined by (3) is in the class $S$.

Proof. From the proof of Theorem 4, we have:

$$
\left|\frac{z h^{\prime \prime}(z)}{h^{\prime}(z)}\right| \leq \sum_{i=1}^{n}\left[\frac{\left|\alpha_{i}-1\right|}{\left|\alpha_{i}\right|}\left|\frac{z f_{i}^{\prime}(z)}{f_{i}(z)}-1\right|+\frac{1}{\left|\alpha_{i}\right|}\left(b_{i}+1\right)\left|\frac{z g_{i}^{\prime}(z)}{g_{i}(z)}-1\right|+\frac{1}{\left|\alpha_{i}\right|} b_{i}\right]
$$

Thus, we obtain:

$$
\begin{gathered}
\frac{1-|z|^{2 \operatorname{Re} \delta}}{\operatorname{Re} \delta}\left|\frac{z h^{\prime \prime}(z)}{h^{\prime}(z)}\right| \\
\leq \frac{1-|z|^{2 \operatorname{Re} \delta}}{\operatorname{Re} \delta} \sum_{i=1}^{n}\left[\frac{\left|\alpha_{i}-1\right|}{\left|\alpha_{i}\right|}\left|\frac{z f_{i}^{\prime}(z)}{f_{i}(z)}-1\right|+\frac{1}{\left|\alpha_{i}\right|}\left(b_{i}+1\right)\left|\frac{z g_{i}^{\prime}(z)}{g_{i}(z)}-1\right|+\frac{1}{\left|\alpha_{i}\right|} b_{i}\right] \\
\leq \frac{1-|z|^{2 \operatorname{Re} \delta}}{\operatorname{Re} \delta} \sum_{i=1}^{n}\left[\frac{\left|\alpha_{i}-1\right|}{\left|\alpha_{i}\right|}\left(\left|\frac{z^{2} f_{i}^{\prime}(z)}{\left[f_{i}(z)\right]^{2}}\right|\left|\frac{f_{i}(z)}{z}\right|+1\right)+\right. \\
\left.+\frac{1}{\left|\alpha_{i}\right|}\left(b_{i}+1\right)\left(\left|\frac{z^{2} g_{i}^{\prime}(z)}{\left.\mid g_{i}(z)\right]^{2}}\right|\left|\frac{g_{i}(z)}{z}\right|+1\right)+\frac{1}{\left|\alpha_{i}\right|} b_{i}\right]
\end{gathered}
$$

Since $\left|f_{i}(z)\right| \leq M_{i},\left|g_{i}(z)\right| \leq N_{i}, z \in \mathcal{U}, i=1, \ldots n$ and each $f_{i}$, each $g_{i}$ satisfy conditions (17) for all $i=1, \ldots, n$, then applying general Schwarz Lemma, we have:

$$
\begin{gathered}
\frac{1-|z|^{2 \operatorname{Re} \delta}}{\operatorname{Re} \delta}\left|\frac{z h^{\prime \prime}(z)}{h^{\prime}(z)}\right| \leq \\
\frac{1-|z|^{2 \operatorname{Re} \delta}}{\operatorname{Re} \delta} \sum_{i=1}^{n}\left[\frac{\left|\alpha_{i}-1\right|}{\left|\alpha_{i}\right|}\left(\left|\frac{z^{2} f_{i}^{\prime}(z)}{\left[f_{i}(z)\right]^{2}}-1\right| M_{i}+M_{i}+1\right)+\right. \\
\left.+\frac{1}{\left|\alpha_{i}\right|}\left(b_{i}+1\right)\left(\left|\frac{z^{2} g_{i}^{\prime}(z)}{\left.\mid g_{i}(z)\right]^{2}}-1\right| N_{i}+N_{i}+1\right)+\frac{1}{\left|\alpha_{i}\right|} b_{i}\right] \\
\leq \frac{1}{\operatorname{Re} \delta} \sum_{i=1}^{n}\left[\frac{\left|\alpha_{i}-1\right|}{\left|\alpha_{i}\right|}\left(2 M_{i}+1\right)+\frac{1}{\left|\alpha_{i}\right|}\left(b_{i}+1\right)\left(2 N_{i}+1\right)+\frac{1}{\left|\alpha_{i}\right|} b_{i}\right]
\end{gathered}
$$




$$
\leq \frac{1}{\operatorname{Re} \delta} \sum_{i=1}^{n} \frac{1}{\left|\alpha_{i}\right|}\left[\left|\alpha_{i}-1\right|\left(2 M_{i}+1\right)+\left(b_{i}+1\right)\left(2 N_{i}+1\right)+b_{i}\right], z \in \mathcal{U},
$$

and from the hypothesis of the Theorem 5, we get:

$$
\frac{1-|z|^{2 \operatorname{Re} \delta}}{\operatorname{Re} \delta}\left|\frac{z h^{\prime \prime}(z)}{h^{\prime}(z)}\right| \leq 1, z \in \mathcal{U}
$$

Applying Theorem 2 for the function $h$, we prove that

$$
I_{\gamma, \alpha_{i}}\left(f_{1}, \ldots, f_{n}, g_{1}, \ldots g_{n}\right) \in S
$$

Let $\alpha_{i}=1$ for all $i=1, \ldots, n$ in Theorem 5 , we have:

Corollary 3. Let $N_{i} \geq 1$, for all $i=1, \ldots, n$ and $\delta \in \mathbb{C}$ with

$$
\operatorname{Re} \delta \geq \sum_{\mathrm{i}=1}^{\mathrm{n}}\left[\left(\mathrm{b}_{\mathrm{i}}+1\right)\left(2 \mathrm{~N}_{\mathrm{i}}+1\right)+\mathrm{b}_{\mathrm{i}}\right]
$$

If for all $i=1, \ldots, n, g_{i} \in G_{b_{i}} ; 0<b_{i} \leq 1$ satisfy

$$
\left|\frac{z^{2} g_{i}^{\prime}(z)}{\left[g_{i}(z)\right]^{2}}-1\right|<1, z \in \mathcal{U}
$$

and $\left|g_{i}(z)\right| \leq N_{i}, z \in \mathcal{U}, i=1,2, \ldots, n$, then for any complex number $\gamma$ with $\operatorname{Re} \gamma \geq \operatorname{Re} \delta$, the integral operator $I_{\gamma}\left(g_{1}, \ldots, g_{n}\right)$ defined by (12) is in the class $S$.

Let $n=1, \alpha_{1}=\alpha, b_{1}=b, M_{1}=M, N_{1}=N$ and $f_{1}=f, g_{1}=g$ in Theorem 5, we have:

Corollary 4. Let $\alpha \in \mathbb{C}^{*}, M \geq 1, N \geq 1$ and $\delta \in \mathcal{C}$ with

$$
\operatorname{Re} \delta \geq \frac{1}{|\alpha|}[|\alpha-1|(2 \mathrm{M}+1)+(\mathrm{b}+1)(2 \mathrm{~N}+1)+\mathrm{b}]
$$

If $f \in \mathcal{A}, g \in G_{b} ; 0<b \leq 1$ satisfy

$$
\left|\frac{z^{2} f^{\prime}(z)}{[f(z)]^{2}}-1\right|<1,\left|\frac{z^{2} g^{\prime}(z)}{[g(z)]^{2}}-1\right|<1, z \in \mathcal{U}
$$

and

$$
|f(z)| \leq M,|g(z)| \leq N, z \in \mathcal{U},
$$

then for any complex $\gamma$ with $\operatorname{Re} \gamma \geq \operatorname{Re} \delta$, the integral operator $I_{\gamma, \alpha}$ defined by (15) is in the class $S$. 
Theorem 6. Let $\alpha_{i} \in \mathbb{C}^{*}$ for all $i=1,2, \ldots n$ and $\gamma \in \mathbb{C}$ with

$$
\operatorname{Re} \gamma \geq \sum_{\mathrm{i}=1}^{\mathrm{n}} \frac{1}{\left|\alpha_{\mathrm{i}}\right|}\left(\left|\alpha_{\mathrm{i}}-1\right|+2 \mathrm{~b}_{\mathrm{i}}+1\right)
$$

and let $c \in \mathbb{C}$ be such that:

$$
|c| \leq 1-\frac{1}{\operatorname{Re} \gamma} \sum_{i=1}^{n} \frac{1}{\left|\alpha_{i}\right|}\left(\left|\alpha_{i}-1\right|+2 b_{i}+1\right)
$$

If for all $i=1, \ldots n, f_{i} \in \mathcal{A}, g_{i} \in G_{b_{i}} ; 0<b_{i} \leq 1$, and

$$
\left|\frac{z f_{i}^{\prime}(z)}{f_{i}(z)}-1\right|<1,\left|\frac{z g_{i}^{\prime}(z)}{g_{i}(z)}-1\right|<1 z \in \mathcal{U}
$$

then the integral operator $I_{\gamma, \alpha_{i}}\left(f_{1}, \ldots, f_{n}, g_{1}, \ldots g_{n}\right)$ defined by (3) is in the class $S$.

Proof. From (9) we deduce that

$$
\begin{array}{r}
\left.|c| z\right|^{2 \gamma}+\left(1-|z|^{2 \gamma}\right) \frac{z h^{\prime \prime}(z)}{\gamma h^{\prime}(z)}|\leq| c|+| \frac{1-|z|^{2 \gamma}}{\gamma}|| \frac{z h^{\prime \prime}(z)}{h^{\prime}(z)} \mid \\
\leq|c|+\left|\frac{1-|z|^{2 \gamma}}{\gamma}\right| \sum_{i=1}^{n} \frac{1}{\left|\alpha_{i}\right|}\left(\left|\alpha_{i}-1\right|+2 b_{i}+1\right) \\
\leq|c|+\frac{1}{|\gamma|} \sum_{i=1}^{n} \frac{1}{\left|\alpha_{i}\right|}\left(\left|\alpha_{i}-1\right|+2 b_{i}+1\right) \\
\leq|c|+\frac{1}{\operatorname{Re} \gamma} \sum_{i=1}^{n} \frac{1}{\left|\alpha_{i}\right|}\left(\left|\alpha_{i}-1\right|+2 b_{i}+1\right) \leq 1
\end{array}
$$

Finally, by applying Theorem 3 , we get that $I_{\gamma, \alpha_{i}}\left(f_{1}, \ldots, f_{n}, g_{1}, \ldots, g_{n}\right) \in S$

Let $\alpha_{i}=1$ for all $i=1, \ldots, n$ in Theorem 6 , we have

Corollary 5. Let $\gamma \in \mathbb{C}^{*}$ with

$$
\operatorname{Re} \gamma \geq \sum_{i=1}^{n}\left(2 b_{i}+1\right)
$$

and let $c \in \mathbb{C}$ be such that

$$
|c| \leq 1-\frac{1}{\operatorname{Re} \gamma} \sum_{i=1}^{n}\left(2 b_{i}+1\right)
$$


If for all $i=1, \ldots, n, g_{i} \in G_{b_{i}} ; 0<b_{i} \leq 1$ and

$$
\left|\frac{z g_{i}^{\prime}(z)}{g_{i}(z)}-1\right|<1, z \in \mathcal{U}
$$

then the integral operator $I_{\gamma}\left(g_{1}, g_{2}, \ldots, g_{n}\right)$ defined by (12) is in the class $S$.

Let $n=1, \alpha_{1}=\alpha, b_{1}=b$ and $f_{1}=f, g_{1}=g$ in Theorem 6 , then we have:

Corollary 6. Let $\alpha \in \mathbb{C}^{*}$ and $\gamma \in \mathbb{C}$ with

$$
\operatorname{Re} \gamma \geq \frac{1}{|\alpha|}(|\alpha-1|+2 \mathrm{~b}+1)
$$

and let $c \in \mathbb{C}$ be such that

$$
|c| \leq 1-\frac{1}{\operatorname{Re} \gamma} \frac{1}{|\alpha|}(|\alpha-1|+2 b+1)
$$

If $f \in \mathcal{A}, g \in G_{b} ; 0<b \leq 1$ satisfy

$$
\left|\frac{z f^{\prime}(z)}{f(z)}-1\right|<1,\left|\frac{z g^{\prime}(z)}{g(z)}-1\right|<1 z \in \mathcal{U}
$$

then the integral operator $I_{\gamma, \alpha}\left(f_{1}, \ldots, f_{n}, g_{1}, \ldots g_{n}\right)$ defined by (15) is in the class $S$.

Theorem 7. Let $\alpha_{i} \in \mathbb{C}^{*}, M_{i} \geq 1, N_{i} \geq 1$ for all $i=1, \ldots, n$ and $\gamma \in \mathbb{C}$ with

$$
\operatorname{Re} \gamma \geq \sum_{\mathrm{i}=1}^{\mathrm{n}} \frac{1}{\left|\alpha_{\mathrm{i}}\right|}\left(\left|\alpha_{\mathrm{i}}-1\right|\left(2 \mathrm{M}_{\mathrm{i}}+1\right)+\left(\mathrm{b}_{\mathrm{i}}+1\right)\left(2 \mathrm{~N}_{\mathrm{i}}+1\right)+\mathrm{b}_{\mathrm{i}}\right)
$$

and let $c \in \mathbb{C}$ be such that

$$
|c| \leq 1-\frac{1}{\operatorname{Re} \gamma} \sum_{i=1}^{n} \frac{1}{\left|\alpha_{i}\right|}\left(\left|\alpha_{i}-1\right|\left(2 M_{i}+1\right)+\left(b_{i}+1\right)\left(2 N_{i}+1\right)+b_{i}\right)
$$

If for all $i=1, \ldots, n, f_{i} \in \mathcal{A}, g_{i} \in G_{b_{i}} ; 0<b_{i} \leq 1$ satisfy

$$
\left|\frac{z^{2} f_{i}^{\prime}(z)}{\left[f_{i}(z)\right]^{2}}-1\right|<1,\left|\frac{z^{2} g_{i}^{\prime}(z)}{\left[g_{i}(z)\right]^{2}}-1\right|<1, z \in \mathcal{U}
$$

then the integral operator $I_{\gamma, \alpha_{i}}\left(f_{1}, \ldots, f_{n}, g_{1}, \ldots, g_{n}\right)$ defined by (3) is in the class $S$. 
Proof. From the proof of the Theorem 5 we have

$$
\begin{array}{r}
\left.|c| z\right|^{2 \gamma}+\left(1-|z|^{2 \gamma}\right) \frac{z h^{\prime \prime}(z)}{\gamma h^{\prime}(z)} \mid \leq \\
|c|+\frac{1}{\operatorname{Re} \gamma} \sum_{i=1}^{n} \frac{1}{\left|\alpha_{i}\right|}\left(\left|\alpha_{i}-1\right|\left(2 M_{i}+1\right)+\left(b_{i}+1\right)\left(2 N_{i}+1\right)+b_{i}\right), z \in \mathcal{U}
\end{array}
$$

which, from the hypothesis of the Theorem 7 , we get:

$$
\left.|c| z\right|^{2 \gamma}+\left(1-|z|^{2 \gamma}\right) \frac{z h^{\prime \prime}(z)}{\gamma h^{\prime}(z)} \mid \leq 1
$$

Applying Theorem 6, for the function $h$, we prove that

$$
I_{\gamma, \alpha_{i}}\left(f_{1}, \ldots, f_{n}, g_{1}, \ldots, g_{n}\right) \in S
$$

Let $\alpha_{i}=1$ for all $i=1, \ldots, n$ in Theorem 4 , we have:

Corollary 7. Let $N_{i} \geq 1$ for all $i=1, \ldots, n$ and $\gamma \in \mathbb{C}$ with

$$
\operatorname{Re} \gamma \geq \sum_{\mathrm{i}=1}^{\mathrm{n}}\left[\left(\mathrm{b}_{\mathrm{i}}+1\right)\left(2 \mathrm{~N}_{\mathrm{i}}+1\right)+\mathrm{b}_{\mathrm{i}}\right]
$$

and let $c \in \mathbb{C}$ be such that

$$
|c| \leq 1-\frac{1}{\mid \operatorname{Re} \gamma} \sum_{i=1}^{n}\left[\left(b_{i}+1\right)\left(2 N_{i}+1\right)+b_{i}\right]
$$

If for all $i=1, \ldots, n, g_{i} \in G_{b_{i}} ; 0<b_{i} \leq 1$, satisfy

$$
\left|\frac{z^{2} g_{i}^{\prime}(z)}{\left[g_{i}(z)\right]^{2}}-1\right|<1, z \in \mathcal{U},
$$

then the integral operator $I_{\gamma}\left(g_{1}, \ldots, g_{n}\right)$ defined by(12) is in the class $S$.

Let $n=1, \alpha_{1}=\alpha, b_{1}=b, M_{1}=M$ and $f_{1}=f, g_{1}=g$ in Theorem 7 , then we have

Corollary 8. Let $\alpha \in \mathbb{C}^{*}, M \geq 1, N \geq 1$ and $\gamma \in \mathbb{C}$ with

$$
\operatorname{Re} \gamma \geq \frac{1}{|\alpha|}[|\alpha-1|(2 \mathrm{M}+1)+(\mathrm{b}+1)(2 \mathrm{~N}+1)+\mathrm{b}]
$$


and let $c \in \mathbb{C}$ be such that

$$
|c| \leq 1-\frac{1}{\operatorname{Re} \gamma}[|\alpha-1|(2 M+1)+(b+1)(2 N+1)+b]
$$

If $f \in \mathcal{A}, g \in G_{b} ; 0<b \leq 1$ satisfy:

$$
\left|\frac{z^{2} f^{\prime}(z)}{[f(z)]^{2}}-1\right|<1,\left|\frac{z^{2} g^{\prime}(z)}{[g(z)]^{2}}-1\right|<1 z \in \mathcal{U}
$$

then the integral operator $I_{\gamma, \alpha}(f, g)$ defined by (15) is in the class $S$.

Remark 1. If $\beta_{i}=\frac{1}{\alpha_{i}}$ and $g_{i}=f_{i}$, for all $i=1, \ldots, n$, in relation (3), we get the integral operator

$$
\begin{gathered}
I_{\gamma}^{\beta_{i}}\left(f_{1}, \ldots f_{n}, g_{1}, \ldots g_{n}\right)(z)= \\
\left\{\gamma \int_{0}^{z} t^{\gamma-1}\left(\frac{f_{1}(t)}{t}\right)^{1-\beta_{1}}\left(f_{1}^{\prime}(t)\right)^{\beta_{1}} \ldots\left(\frac{f_{n}(t)}{t}\right)^{1-\beta_{n}}\left(f_{n}^{\prime}(t)\right)^{\beta_{n}} d t\right\}^{\frac{1}{\gamma}},
\end{gathered}
$$

studied by B. A. Frasin in [3].

Remark 2. For $\beta_{i}=1-\frac{1}{\alpha_{i}}$ and $g_{i}^{\prime}(t)=1$ for all $i=1, \ldots, n$, in relation (3), we get the integral operator $G(z)=\left\{\gamma \int_{0}^{z} t^{\gamma-1} \prod_{i=1}^{n}\left(\frac{f_{i}(t)}{t}\right)^{\beta_{i}} d t\right\}^{\frac{1}{\gamma}}, z \in \mathcal{U}$ studied by D. Breaz and N. Breaz in [1].

Remark 3. If instead of $1-\frac{1}{\alpha_{i}}$ we consider $\alpha_{i}, g_{i}^{\prime}(t)=1$, and if instead of $f_{i}(t)$ we have $\mathcal{D}_{\lambda}^{n, \gamma} f_{i}(t)$ for all $i=1, \ldots, n$ in relation (3), we get the integral operator

$$
\begin{gathered}
I_{\beta}^{n, \gamma}\left(f_{1}, \ldots, f_{m}\right): \mathcal{A}^{m} \rightarrow \mathcal{A} \\
I_{\beta}^{n, \gamma}\left(f_{1}, f_{2}, \ldots, f_{m}\right)(z)=\left\{\beta \int_{0}^{z} t^{\beta-1} \prod_{i=1}^{m}\left(\frac{\mathcal{D}_{\lambda}^{n, \gamma} f_{i}(t)}{t}\right)^{\alpha_{i}} d t\right\}^{\frac{1}{\beta}}, z \in \mathcal{U}
\end{gathered}
$$

where $\mathcal{D}_{\lambda}^{n, \gamma}$ is the generalized Al-Oboudi differenatial operator, defined and studied by S. Bulut in [2].

\section{Acknowledgment}

This work was partially supported by the strategic project PERFORM, POSDRU 159/1.5/S/138963, inside POSDRU Romania 2014, co-financed by the European Social Fund-Investing in People. 


\section{References}

[1] Breaz, D., Breaz, N., Two integral operators, Studia Universitatis Babes Bolyai, Mathematica, Cluj Napoca, 3 (2002),13-21 .

[2] Bulut, S., Univalence preserving integral operators defined by generalized Al-Oboudi differential operators, Analele Ştiinţifice ale Universităţii "Ovidius" Constanţa, Volumul XVII (2009), fascicola 1, pp 37-50.

[3] Frasin, B.A., Univalence criteria for general integral operator, Mathematical Communications, 16 (2011),115-124.

[4] Mayer, O., The Function Theory of One Variable Complex, Bucureşti, 1981.

[5] Pascu, N.N., On a univalence criterion II, Itinerant Seminar on Functional Equations Approximation and Convexity, Cluj-Napoca,1985, pp.153-154.

[6] Pascu, N.N.,An improvment of Becker's univalence criterion, Proceedings of the Commemorative Session Simion Stoilov, Braşov,1987.

[7] Pescar, V., A new generalization of Ahlfors's and Becker's criterion of univalence, Bull. Malaysian Math. Soc. (2) 19 (1996), no.2, 53-54.

[8] Pescar, V., Breaz, D., On an integral operator, Analele Ştiinţifice ale Universităţii "Ovidius" Constanţa, 2014, Vol. 22, fascicola 3, pp 169-177.

[9] Silverman, H.,Convex and starlike criteria, Int.J. Math., Sci 22 (1999), 75-79.

Adriana OPREA,

Department of Mathematics,

University of Piteşti,

Târgul din Vale Str., No. 1, 110040, Piteşti, Argeş, Romania.

Email: adriana_oprea@yahoo.com

Daniel BREAZ ,

Department of Mathematics,

"1 Decembrie 1918" University of Alba Iulia,

N. Iorga Str., No 11-13, 510009 Alba Iulia, Alba, Romania.

Email: dbreaz@uab.ro 